\title{
Prediction of Anxiety Based on Children's Coping Behavior
}

\author{
Behnaz Hajimirarab1, \\ Changiz Rahimi2
}

\section{Norollah mohammadi ${ }^{3}$}

\begin{abstract}
${ }^{1}$ Faculty of Education and Psychology, Department of clinical psychology, Shiraz University, Shiraz, Iran 2Faculty of Education and Psychology, Department of clinical psychology, Shiraz University, Shiraz, Iran 3Faculty of Education and Psychology, Department of clinical psychology, Shiraz University, Shiraz, Iran *Corresponding Author: Behnaz Hajimirarab; Email:behnazi77@yahoo.com
\end{abstract}

\section{Doi:10.5901/mjss.2016.v7n2s1p387}

\section{Abstract}

The purpose of this study was to predict anxiety in children based on their coping behaviors. Participants included 400 children aged $9-13$ years enrolled in a summer camp in Dubai from different nationalities (Iranian, Arab, European) in both genders. The sample consisted of 150 children (50 from Iran, 50 From Europe and 50 Arabs) who were randomly selected. Subjects completed children's anxiety and coping behaviors questionnaires. To analyze the data, correlation and stepwise regression analysis were performed using SPSS software. Results of regression analysis showed a significant effect of dealing with the problem and destructive behavior on anxiety. However, the effect of diversion of problem was not significant on anxiety. The results showed that the coping behaviors of children are able to predict anxiety.

Keywords: Coping behaviors, anxiety.

\section{Introduction}

Anxiety disorder is the most common form of pathology in children and adolescents (Pine, Helfinstein, Bar-Haim, Nelson and Fox, 2008; Eysenck, 2013). Numerous studies indicate the increasing prevalence of the disorder in children; this has caused concerns of researchers to study the symptoms of anxiety disorders in children and adolescents in the past decade. In fact, vulnerability to depression, anxiety and anger is based on a core belief about self or others; these beliefs form in the early childhood. Any change in life, whether significant or less, is stressful and people are forced to cope; however, these pressures are not always bad and unpleasant. How to deal with these conditions and strategies which one chooses to cope with them are considered as a part of vulnerability profile, while taking advantage of bad strategies in coping stressful factors can lead to problems (Daeipoor, 1999). Studies show a link between coping behaviors and psychiatric disorders and mental health in adults and teenagers (Wong, Leung \& So, 2001; Haller et al., 2014). Lazarus and Folkman believe that coping is a mediator between negative events and mental health. According to George Albee (1982), one of the essential components of mental health is efficient coping skill. Studies have shown that inefficient coping behaviors can expose children and adolescents to behavioral problems such as aggression, depression and anxiety while dealing with pressures and tensions of life (Elgar, Arlett \& Groves, 2003). In fact, coping behaviors are divided into two types of efficient and inefficient behaviors, appearing in children as diversion of problem, coping with the problems to solve them and destructive coping (inefficient) (Hernandez, 2008). Anxiety is one of the most common psychiatric disorders during childhood. The lack of an accurate diagnosis of anxiety in children by parents and complete inability of children to manifest anxiety urge us not to overlook anxiety in children. Anxiety disorders in children can lead to more problems in adulthood, such as inability to function in a normal social environment such as school and workplace, ability to engage with peers in social levels, poor self-concept and adult anxiety disorders and other mental health problems, if not treated in time.

Therefore, it is vital to predict cognitive schema of anxiety. That seems to explain the cognitive and pathological structure of anxiety symptoms in children; anxiety in 9-13 year-old children can be predicted by vulnerability, alienation and subjugation. However, little is known in this regard, requiring further investigation. The purpose of this study was to predict anxiety based on coping behaviors in children aged $9-13$ years enrolled in Dubai Summer Camp which is held by the Association of Woman and Child Protection. 


\section{Theoretical Background}

\subsection{Anxiety}

Anxiety is a highly unpleasant and vague state which is often associated with worry and one or more vague symptoms, such as dyspnea in the chest, palpitations, sweating, headache and restlessness (Kaplan \& Sadock, 1996). The prevalence of anxiety disorders in children are estimated to be about 10\% (Egger \& Angold, 2006). Anxiety disorders are relatively stable over time and expose children at increased risk of depression, substance abuse and poor academic performance in the future (Whiteside \& Brown, 2008; Rapee, Schniering \& Hudson, 2009). Anxiety symptoms include anger, aggression, destructive behavior, mood swings, aggressive movements, destructive impact on individual communications such as avoiding behaviors or excessive dependence (Khodayarifard \& Shokuhi-yekta, 2005). Types of anxiety include chronic anxiety and acute stress (Spielberger \& Sarason, 2013). Factors affecting children anxiety include biological and physical factors, environmental and social factors and genetic and hereditary factors (Rask-Andersen et al., 2013).

\subsection{Coping Behavior}

Coping is one of the variables which are widely studied in the context of health psychology (Moon et al., 2014). Coping refers to a psychological process, the cognitive and behavioral efforts to resolve stressful conditions. Coping involves efforts, including action-oriented and intrapsychic, to manage environmental and internal demands and conflict between them (Tashimova et al., 2014). In fact, coping is a set of behavioral and cognitive activities and processes to prevent, manage or reduce stress (Veenit et al., 2014). Coping behavior is individual behavioral efforts when faced with psychological pressures to overcome, tolerate, or minimize the effects of stress (Lazarus \& Folkman, 1984). Three coping styles which people employ are: surrender: when people surrender schema, they accept its validity and they never try to fight with schema or avoid it, but accept that the schema is correct. Avoidance: when people adopt avoidance, they try to live in a way that the schema never activates. They try to live in ignorance, as if there is no schema (Young et al., 2003). Overcompensation: people fight the schema through thought, emotion, behavior and interpersonal relations as if their schemas are different. They try to be different from their childhood, i.e. the time of formation of schemas, as much as possible (Köse, 2009).

\section{Literature Review}

Sabri-Nazarzadeh (2010) examined the relationship between the sense of unity and psychological hard work and mental health and stress coping strategies. The findings suggest a significant negative relationship between the sense of unity and hard work and the emotion-based coping strategy and a positive significant relationship between the sense of unity and hard-working and health.

Boroujerdi (2011) examined the interactive relationship between attachment styles, coping styles and mental health in male adolescents aged 17 to 20 hospitalized with cancer in Tehran. The hypotheses of this study were rejected; she found no significant relationship between the type of attachment style and the use of problem-based or emotionbased coping strategies in male adolescents with cancer.

Sadaghiani (2013) compared coping styles of subjects with depression and anxiety and normal people. The main objective of this study was to compare non-clinical population with depression, anxiety, stress and normal people based on conscious style. The findings indicated that emotion-based coping and avoidance could play an important role as median or an effective factor of negative effects such as depression, anxiety and stress.

Horney et al (2011) examined the relationship between quality of life, coping styles, optimism, anxiety and depression in patients. The results showed that the use of negative coping styles was related to high levels of anxiety and lower levels of optimism was associated with higher levels of depression.

Mahmoud et al (2012) investigated the relationship between stress coping styles, anxiety and depression. The results showed that inefficient styles predicted stress, anxiety and depression. Effective styles were not significant predictor of stress, anxiety and depression.

Moon et al (2014) examined the characteristics of stress coping behavior in patients with bipolar disorders. The findings suggest that coping strategies are more in patients with bipolar maladaptive than normal ones.

Yansheng et al (2013) investigated test anxiety and coping behavior of high school students. The findings suggested that high school students suffered high levels of test anxiety. In dealing with test anxiety, feelings are given 
priority, especially for girls who encounter more problems dealing with test anxiety.

\section{Research Methodology}

This research is a descriptive correlational research. The study considered coping behaviors as predictor variables and anxiety in children as the criterion. The participants included children aged 9-13 years enrolled in a summer camp in Dubai from different nationalities (Iranian, Arab, European), in both genders. Dubai Summer Camp is held to fill leisure time of students during holiday. A variety of activities such as music, sports and cultural programs is performed for all nations. Summer Camp is the center of Association for Woman and Child Protection in Dubai, covering an average of 400 children. The sample consisted of 150 children aged 9-13 years who were studying in fourth to eighth grade. The samples were randomly selected. A list of registration numbers were provided in the center and 50 Iranian, 50 European and 50 Arab students were selected randomly. In total, there were 90 boys and 60 girls in three groups.

\section{Measurements}

RCMAS: this study used the Revised Children's Manifest Anxiety Scale (RCMAS) to measure anxiety. The scale was developed to assess the amount and quality of children's anxiety (Gerard \& Reynolds, 1999). The scale was adopted from Children's Manifest Anxiety Scale (CMAS) of Kastnda, Mac Kandls and Palermo (1956). RCMAS test is suitable for those aged 6 to 19. The scale can be run by teachers, researchers and therapists on individuals. RCMAS includes 37 questions (28 for anxiety and 9 lie detector) responded by yes or no. Each item is scored zero or one; therefore, the scores will vary from 0 to 28 for items related to anxiety and from 0 to 9 for items related to lie detector. The lower score of anxiety scale indicates lower levels of anxiety and lower score of lie detector indicates honesty.

In Iran, Taghavi and Alishahi (2003) examined the reliability and validity of RCMAS. Reliability of RCMAS was examined by test-retest and split-half ( 0.67 and 0.66 , respectively) and validity qualified the scale for use.

CCBQ: Children's Coping Behavior Questionnaire (CCBQ) developed by Hernandez (2008) contains 57 statements and 3 scales including diversion of problem, coping with problem to solve it and destructive coping which is scored on a four-point Likert type ( 1 = never, 2 = sometimes, 3 = often, $4=$ almost always). Hernandez (2008) obtained Cronbach's alpha for all three scales (0.94).

Since the validity and reliability of the questionnaires are not clear in Dubai and no study have been conducted by these questionnaires in Dubai, the author examined the reliability and validity of the questionnaire. In this study, Cronbach's alpha was used to determine the reliability. This method is used for calculating the internal consistency of material which measures various properties. Table 1 reports Cronbach's alpha for the used questionnaires. According to Table 1, the questionnaires and subscales were sufficiently reliable. In CCBQ, the highest Cronbach's alpha belongs to diversion of problem (0.90) and the lowest alpha is related to coping with problem (0.78). In RCMAS, the highest alpha is 0.92 for all subscales.

Table 1: Cronbach's alpha for the variables

\begin{tabular}{|l|l|c|}
\hline Test & Subscale & Cronbach's alpha \\
\hline \multirow{3}{*}{ CCBQ } & Diversion of problem & 0.90 \\
\cline { 2 - 3 } & Coping with problems & 0.78 \\
\cline { 2 - 3 } & Destructive coping & 0.79 \\
\hline \multirow{2}{*}{ RCMAS } & $\mathbf{0 . 9 2}$ \\
\hline
\end{tabular}

Confirmatory factor analysis was used to assess the validity of RCMAS. Table 2 lists factor loadings and the explained variance of questions related to anxiety. Obviously, the remaining questions of the analysis have significant factor loadings on anxiety. Questions 9, 17, 25, 29, 30 and 33 were excluded from the analysis due to their lower and nonsignificant loadings.

Table 2: Factor loadings, explained variance of items

\begin{tabular}{|c|c|c|c|c|c|}
\hline Question & Factor loading & Explained variance & Question & Factor loading & Explained variance \\
\hline 1 & 0.36 & $13 \%$ & 18 & 0.72 & $52 \%$ \\
\hline 2 & 0.57 & $32 \%$ & 19 & 0.38 & $14 \%$ \\
\hline 3 & 0.47 & $22 \%$ & 21 & 0.44 & $19 \%$ \\
\hline
\end{tabular}




\begin{tabular}{|c|c|c|c|c|c|}
\hline 5 & 0.56 & $31 \%$ & 22 & 0.95 & $90 \%$ \\
\hline 6 & 0.97 & $94 \%$ & 23 & 0.59 & $35 \%$ \\
\hline 7 & 0.57 & $32 \%$ & 26 & 0.62 & $38 \%$ \\
\hline 10 & 0.49 & $24 \%$ & 27 & 0.52 & $27 \%$ \\
\hline 11 & 0.81 & $66 \%$ & 31 & 0.38 & $14 \%$ \\
\hline 13 & 0.48 & $23 \%$ & 34 & 0.48 & $23 \%$ \\
\hline 14 & 0.91 & 0.83 & 35 & 0.57 & $32 \%$ \\
\hline
\end{tabular}

As Table shows, $\chi^{2 / d f}$ and RMSEA were acceptable and indices GFI, AGFI, CFI and NFI were also acceptable. Therefore, data are well fitted to the scale.

Table 3: Fitting indicators of RCMAS

\begin{tabular}{|l|c|}
\hline Characteristic & Estimates \\
\hline$\chi^{2 / d f}$ & 1.52 \\
\hline RMSEA & 0.068 \\
\hline Goodness of fit index (GFI) & 0.94 \\
\hline Adjusted goodness of fit index (AGF)I & 0.92 \\
\hline Comparative fitness index (CFI) & 0.98 \\
\hline Soft fitness index (NFI) & 0.96 \\
\hline
\end{tabular}

Confirmatory factor analysis was used to assess the validity of CCBQ. Table 4 lists factor loadings and the explained variance of questions related to diversion of problem. Questions 1, 2, 8, 20 and 51 were excluded from the analysis due to their lower and non-significant loadings.

Table 4: Factor loadings and explained variance of diversion of problem

\begin{tabular}{|c|c|c|c|c|c|}
\hline Question & Factor loading & Explained variance & Question & Factor loading & Explained variance \\
\hline 3 & 0.35 & $12 \%$ & 39 & 0.86 & $74 \%$ \\
\hline 4 & 0.65 & $43 \%$ & 40 & 0.56 & $31 \%$ \\
\hline 5 & 0.35 & $12 \%$ & 41 & 0.37 & $14 \%$ \\
\hline 7 & 0.79 & $63 \%$ & 43 & 0.41 & $17 \%$ \\
\hline 9 & 0.36 & $13 \%$ & 44 & 0.56 & $32 \%$ \\
\hline 10 & 0.65 & $43 \%$ & 45 & 0.37 & $14 \%$ \\
\hline 13 & 0.66 & $44 \%$ & 48 & 0.47 & $22 \%$ \\
\hline 16 & 0.51 & $26 \%$ & 49 & 0.42 & $18 \%$ \\
\hline 19 & 0.55 & $30 \%$ & 50 & 0.45 & $20 \%$ \\
\hline 19 & 0.55 & $30 \%$ & 55 & 0.64 & $41 \%$ \\
\hline 21 & 0.39 & $15 \%$ & 56 & 0.71 & $51 \%$ \\
\hline 27 & 0.54 & $29 \%$ & 57 & 0.62 & $38 \%$ \\
\hline 32 & 0.65 & $43 \%$ & \multicolumn{3}{|l}{} \\
\hline
\end{tabular}

Table 5 lists factor loadings and the explained variance of questions related to coping with problem. Questions 35 and 29 were excluded from the analysis due to their lower and non-significant loadings.

Table 5: Factor loadings and explained variance of coping with problem

\begin{tabular}{|c|c|c|c|c|c|}
\hline Explained variance & Factor loading & Question & Explained variance & Factor loading & Question \\
\hline $14 \%$ & 0.37 & 34 & $15 \%$ & 0.39 & 15 \\
\hline $24 \%$ & 0.49 & 35 & $50 \%$ & 0.71 & 17 \\
\hline $48 \%$ & 0.69 & 36 & $23 \%$ & 0.48 & 22 \\
\hline $34 \%$ & 0.58 & 38 & $16 \%$ & 0.40 & 28 \\
\hline $44 \%$ & 0.66 & 46 & $34 \%$ & 0.58 & 30 \\
\hline $31 \%$ & 0.56 & 47 & $20 \%$ & 0.45 & 31 \\
\hline
\end{tabular}

Table 6 lists factor loadings and the explained variance of questions related to destructive coping. Questions 12, 19 and 
33 were excluded from the analysis due to their lower and non-significant loadings.

Table 6: Factor loadings and explained variance of destructive coping

\begin{tabular}{|c|c|c|c|c|c|}
\hline Question & Factor loading & Explained variance & Question & Factor loading & Explained variance \\
\hline 5 & $51 \%$ & $26 \%$ & 37 & 0.32 & $10 \%$ \\
\hline 6 & 0.46 & $21 \%$ & 42 & 0.32 & $10 \%$ \\
\hline 11 & 0.56 & $32 \%$ & 52 & 0.40 & $16 \%$ \\
\hline 18 & 0.88 & $78 \%$ & 53 & 0.66 & $44 \%$ \\
\hline 25 & 0.53 & $28 \%$ & 54 & 0.62 & $38 \%$ \\
\hline 26 & 0.33 & $11 \%$ & \multicolumn{4}{l}{} \\
\hline
\end{tabular}

As Table 7 shows, $\chi^{2} / \mathrm{df}$ and RMSEA were acceptable and indices GFI, AGFI, CFI and NFI were also acceptable. Therefore, data are well fitted to the scale.

Table 7: Fitting indices of coping behaviors

\begin{tabular}{|l|c|}
\hline Characteristic & Estimates \\
\hline$\chi^{2}$ df & 1.26 \\
\hline RMSEA & 0.048 \\
\hline Goodness of fit index (GFI) & 0.94 \\
\hline Adjusted goodness of fit index (AGFI) & 091 \\
\hline Comparative fitness index (CFI) & 0.99 \\
\hline Soft fitness index (NFI) & 0.98 \\
\hline
\end{tabular}

\section{Methods}

This study evaluated children ages 9-13 years from Iranian, Arabs and Europeans nationals as samples. The inventories were randomly distributed for groups of 10 children at rest time. Subjects participated voluntarily in the study. The sample was available; therefore, both girls and boys participated in the study. However, their participation was not equal. Data analysis was performed by descriptive indexes (mean and standard deviation), Pearson correlation and stepwise regression using SPSS 18 software. In addition, confirmatory factor analysis was used to check the validity of materials by LISREL software.

\section{Results}

\subsection{Descriptive Statistics}

Table 8 lists descriptive statistics for the sample including mean, standard deviation, minimum and maximum score of each variable.

Table 8: Descriptive indicators

\begin{tabular}{|l|l|c|c|}
\hline Test & Subscale & Mean & Standard Deviation \\
\hline \multirow{3}{*}{ CCBQ } & Diversion of problem & 57.77 & 13.66 \\
\cline { 2 - 4 } & Coping with problems & 27.39 & 6.87 \\
\cline { 2 - 4 } & Destructive coping & 19.74 & 5.65 \\
\hline RCMAS & 9.03 & 6.55 \\
\hline
\end{tabular}

\subsection{Inferential Statistics}

Do coping behaviors predict anxiety symptoms in children?

Before answering this question, the correlation matrix of variables is given.

Table 9: The correlation matrix of coping behavior with anxiety

\begin{tabular}{|l|c|c|c|}
\hline Variable & Diversion of problem & Coping with problem & Destructive coping \\
\hline Anxiety & $-0.17^{*}$ & $-0.37^{* *}$ & $-0.31^{* * *}$ \\
\hline
\end{tabular}


$\mathrm{P}<0 / 01,{ }^{*} \mathrm{P}<0 / 05^{* *}$

As seen in Table 9, there is a negative significant relationship between diversion of problem and coping with problem and anxiety, but a positive significant relationship between destructive coping and anxiety.

To answer the second question, the stepwise regression method was used.

To predict anxiety by coping behaviors, coping with problem and destructive coping were incorporated in the equation respectively. These variables maintained their significance through two steps. Diversion of problem was excluded from the analysis because it did not reach significant level. Regression analysis results are presented in Table 10.

Table 10: Results of stepwise regression analysis for anxiety based on coping behaviors

$\mid$\begin{tabular}{|l|c|c|c|c|c|c|c|}
\hline Variables & $\mathrm{R}$ & $\mathrm{R}^{2}$ & Adjusted $\mathrm{R}^{2}$ & $\mathrm{SE}$ & $\Delta \mathrm{R}^{2}$ & $\mathrm{~F}$ & $\mathrm{df}$ \\
\hline Coping with problems & 0.38 & 0.14 & 0.126 & 6.08 & 0.142 & $23.110^{* *}$ & 1140 \\
\hline Destructive coping & 0.61 & 0.38 & 0.376 & 5.20 & 0.234 & $52.058^{* *}$ & 2139 \\
\hline
\end{tabular}
** $\mathrm{P}<0.001$

According to Table 10, coping with problem and destructive coping predict variations in anxiety by $14.2 \%$ and $23.4 \%$, respectively. These variables can predict about $37.6 \%$ of variations in anxiety of children. As shown in Table 10, the results of analysis of variance (ANOVA) show that coping with problem and destructive coping significantly influence anxiety in children.

Table 11: Stepwise regression analysis of anxiety based on coping behaviors

\begin{tabular}{|l|l|c|c|c|c|c|c|}
\hline Steps & Predictor variable & Standard coefficients $\beta$ & SM & Non-standard coefficient B & t & Sig. & Constant a \\
\hline Step 1 & Coping with problem & -0.38 & 0.07 & -0.353 & -4.807 & 0.001 & 18.559 \\
\hline \multirow{2}{*}{ Step 2 } & Coping with problem & -0.58 & 0.07 & -0.547 & -8.006 & 0.001 & \multirow{2}{*}{12.005} \\
\cline { 2 - 7 } & Destructive coping & 0.53 & 0.08 & 0.605 & 7.215 & 0.001 & \\
\hline
\end{tabular}

As shown in Table 11, T-values show significant effects of coping with problem and destructive coping on anxiety in children. The results of regression analysis showed that coping with problem and destructive coping significantly influence anxiety symptoms in children, while the effect of diversion from problem is not significant on anxiety.

\section{Conclusion}

To find that whether coping behaviors can predict anxiety symptoms in children, correlation matrix of variables relating to this question showed a negative significant relationship between diversion of problem $(-0.17)$ and coping with problem (0.37 ) and anxiety, but a positive significant relationship between destructive coping and anxiety (0.31).

To examine the role of coping behaviors in anxiety symptoms of children, the stepwise regression method was used. To predict anxiety by coping behaviors, coping with problem and destructive coping were incorporated in the equation. These two variables maintained significant through two steps. Diversion of problem was excluded from the analysis, because it did not reach significant level. The results showed that coping with problem and destructive coping could predict the variations in anxiety by $14.2 \%$ and $23.4 \%$, respectively. These variables are able to predict variations in anxiety of children by $37.6 \%$.

The findings of this study are consistent with Horney et al. (2011), who showed that the use of negative coping styles were related with high levels of anxiety. The findings are also consistent with Mahmoud et al. (2012), who showed that coping styles could predict stress, anxiety and depression.

Individuals may present different emotional and behavioral symptoms of anxiety. Therefore, these symptoms should be identified for early diagnosis and treatment. The study was an attempt to predict anxiety by coping behaviors in children. The results showed that destructive coping, coping with problems and diversion of problem are correlated with anxiety. There is a negative significant relationship between diversion of problem and coping with problem and anxiety, but a positive significant relationship between destructive coping and anxiety. coping with problem and destructive coping predict variations in anxiety by $14.2 \%$ and $23.4 \%$, respectively. These variables can predict about $37.6 \%$ of variations in anxiety of children. The increase in diversion of problem and coping with problem decreases anxiety symptoms; thus, they are negatively correlated. While destructive coping is positively correlated with anxiety symptoms; thus, the increase 
in destructive coping increases anxiety symptoms in children and vice versa.

\section{Limitations}

1. The lack of similar studies in Dubai to compare the results of present study with the results of similar studies.

2. Inability to generalize the results to other populations, because any population is influenced by its own cultural, contextual and educational characteristics.

\section{Suggestions}

1. According to the findings in the field of children's anxiety, the process of transformation and treatment in detecting symptoms of anxiety disorders in children should be better understood and recognized;

2. Anxiety influences the cognitive level and expands mental activity irregularly. According to findings, vulnerability, alienation, undeveloped self, subjugation, defectiveness, failure and mistrust/abuse predict anxiety by $53 \%, 17.6 \%, 4.9 \%, 2.4 \% 1.8 \%, 1.9 \%$ and $0.5 \%$, respectively. Therefore, these symptoms should be identified for early diagnosis and treatment;

3. Based on findings, anxiety also influences physical activity causing violent movements and confusion. Therefore, children need to receive trainings to cope anxiety in school and families.

\section{References}

Castaneda, A., McCandless, B. R., \& Palermo, D. S. (1956). The children's form of the manifest anxiety scale. Child development, 317326.

Daeipoor, P., (1999). Coping scale of adolscents in Tehran, Master Thesis, Tehran Psychiatric Institute

Egger, H. L., \& Angold, A. (2006). Common emotional and behavioral disorders in preschool children: presentation, nosology, and epidemiology. Journal of Child Psychology and Psychiatry, 47(34), 313-337.

Elgar, F. J., Arlett, C., \& Groves, R. (2003). Stress, coping, and behavioural problems among rural and urban adolescents. Journal of Adolescence, 26(5), 574-585.

Eysenck, M. W. (2013). Anxiety: The cognitive perspective. Psychology Press. Eysenck, M. W. (2013). Anxiety: The Cognitive Perspective. New York, YN: Psychology Press.

Gerard, A., \& Reynolds, C. (1999). Characteristics and applications of the revised children's manifest anxiety scale. The use of psychological testing for treatment and planning and outcomes assessment, 2, 323-340.

Ghasem-Boroujerdi, F., (2011). the interactive relationship between attachment styles, coping styles and mental health of male adolescents aged 17-20 years hospitalized with cancer in tehran, s.l.: s.n.

Haller, J., Aliczki, M., Pelczer, K. G., Spitzer, K., Balogh, Z., \& Kantor, S. (2014). Effects of the fatty acid amide hydrolase inhibitor URB597 on coping behavior under challenging conditions in mice. Psychopharmacology, 231(3), 593-601.

Hernandez, B. C. (2008). The children's coping behavior questionnaire: Development and validation (Doctoral dissertation, Faculty of the Louisiana State University and Agricultural and Mechanical College in partial fulfillment of the requirements for the degree of Master of Arts in The Department of Psychology by Brittany C. Hernandez BA, Loyola University New Orleans).

Horney, D. J., Smith, H. E., McGurk, M., Weinman, J., Herold, J., Altman, K., \& Llewellyn, C. D. (2011). Associations between quality of life, coping styles, optimism, and anxiety and depression in pretreatment patients with head and neck cancer. Head \& neck, 33(1), 65-71.

Kaplan, H. I., \& Sadock, B. J. (1996). Pocket handbook of psychiatric drug treatment. Williams \& Wilkins.

Khodaakhshi-Kulai, A., Baseri-Salehi, N., Roshan, R. \& Falsafinejad, M., (2014). comparison of maladaptive cognitive schemas, nonrational beliefs and communicational skills in foster and non-foster adolescents. Psychiatric Nursing, 2(1), pp. 1-12.

Khodayarifard, M. \& Shokuhi-yekta, M., 2005. Diagnosis and treatment of psychological disorders in children and adolescents. Tehran: Yastarun Press, Tehran, Iran.

Köse, B. (2009). Associations of psychological well-being with early maladaptive schemas and self-construals (doctoral dissertation, Middle East technical university).

Lazarus, s. \& folkman, s. (1984), stress Appraisal and coping, New York: Springer.

Mahmoud, J. S. R., Staten, R. T., Hall, L. A., \& Lennie, T. A. (2012). The relationship among young adult college students' depression, anxiety, stress, demographics, life satisfaction, and coping styles. Issues in Mental Health Nursing, 33(3), 149-156.

Moon, E, Chang, J. S, Choi, S, Hyon Ha, T, Cha, B, Cho, H, S, Park, J. M, Lee, B. D, Lee, Y. M, Choi, Y, Ha, K (2014), Characteristics of stress-coping behaviors in patients with bipolar disorders, Psychiatry Research, 218(1-2), 69-74.

Pine, D. S., Helfinstein, S. M., Bar-Haim, Y., Nelson, E., \& Fox, N. A. (2008). Challenges in developing novel treatments for childhood disorders: lessons from research on anxiety. Neuropsychopharmacology, 34(1), 213-228.

Rapee, R. M., Schniering, C. A., \& Hudson, J. L. (2009). Anxiety disorders during childhood and adolescence: origins and treatment. Annual Review of Clinical Psychology, 5, 311-341.

Rask-Andersen, A., Lampa, E., Janson, C., \& Leander, M. (2013). Impact of Anxiety and Depression on Respiratory 
Symptoms. Occupational and Environmental Medicine, 1(1), 2-13.

Reynolds, C. R., \& Richmond, B. O. (1978). What I think and feel: A revised measure of children's manifest anxiety. Journal of abnormal child psychology, 6(2), 271-280.

Sabri-Nazarzadeh, R., 2010. the relationship between the sense of unity and psychological hard working and mental health and stress coping strategies, Master Thesis, Ferdowsi University of Mashhad, Iran.

Sadaghiani, N. S. K. (2013). The Comparison of Coping Styles in Depressed, Anxious, Under Stress Individuals and the Normal Ones. Procedia-Social and Behavioral Sciences, 84, 615-620.

Spielberger, C. D., \& Sarason, I. G. (Eds.). (2013). Stress and Emotion: Anxiety, Anger, \& Curiosity. Washington, DC, US: Taylor \& Francis.

Taghavi, S.-M. \& Alishahi, M., (2003). reliability and validity of CMAS. psychology, 7(4), pp. 342-357.

Tashimova, F, Pfeifer, N, Burdina, E, Kudysheva, A, Pigovaeva, N. (2014), Dependence of Student's Educational Activity Meanings on the Peculiarities ofCoping Behavior, Procedia - Social and Behavioral Sciences,136, 506-510.

Veenit, V, Riccio, O., \& Sandi C. (2014), CRHR1 links peripuberty stress with deficits in social and stress-coping behaviors. Journal of Psychiatric Research, 53, 1-7.

Whiteside, S. P., \& Brown, A. M. (2008). Exploring the utility of the Spence Children's Anxiety Scales parent-and child-report forms in a North American sample. Journal of Anxiety Disorders, 22(8), 1440-1446.

Wong, D. F. K., Leung, S. S. K., \& So, C. K. O. (2001). Differential impacts of coping strategies on the mental health of Chinese nurses in hospitals in Hong Kong. International Journal of Nursing Practice, 7(3), 188-198.

Yansheng, H., Yu, T., \& Dexin, C. (2013). The Status Quo of Test Anxiety and Coping Behavior of Senior Students in Guangzhou High School. China Journal of Health Psychology, 1, 045.

Young, J. E., Klosko, J. S., \& Weishaar, M. E. (2003). Schema therapy: A practitioner's guide. New York, YN: Guilford Press. 